\title{
Need for the Intercultural Awareness in Erasmus Mobility - Administrative Point of View
}

\author{
Tatjana Welzer, Marjan Družovec, Marko Hölbl, and Mirjam Bonačić \\ Faculty of Electrical Engineering and Computer Science, University of Maribor \\ Smetanova 17, Maribor, Slovenia \\ \{welzer, marjan.druzovec, marko.holbl, mirjam.bonacic\}@uni-mb.si
}

\begin{abstract}
In recent years, mobility has become one of the most important goals inside the European Union (EU). Different projects and programs support the mobility of students, teachers and other employed persons. From program to program and project to project, goals are different. Through employment, companies have the need for different experts or the need to work with international teams. They can also offer jobs for placements and for young experts for their first employment (like the Leonardo da Vinci program), while for students and teachers, the main goals of mobility are learning and teaching in different environments (like the Erasmus program) as well as learning languages and benefiting from cross-cultural experiences. Both students and teachers come from different cultural environments and the host organisation has to take care of intercultural awareness in all levels of activities, from administration up to teaching and passing exams.
\end{abstract}

Keywords: Lifelong learning, mobility, cultural awareness, intercultural dialogue.

\section{Introduction}

Since 2007 EC is running the Lifelong Learning Program, which is like an umbrella covering different programs and projects that support mobility of participants. One of those programs is also Erasmus. Erasmus students' mobility has already been running for years and different universities have collected a lot of experiences in different fields. One rarely mentioned area is administrative experience. Depending on the level of organization within the university, these administration experiences can be collected on different levels. We would like to concentrate on the faculty level. The Faculty of Electrical Engineering and Computer Science, at the University of Maribor [1], [2], does not have its own international relations office, so the administrative part is covered partly by existing staff in the students' office and primarily by the Erasmus Coordinator and International Co-operations Assistant, who are mostly responsible for administrative work (besides the student's office). Both the coordinator as well as the co-operation assistant need to have a lot of experience - not only with mobility, education programs, law conditions and such things, but also with intercultural awareness. They are involved in intercultural dialogue daily via their communication 
with incoming students as well as outgoing students and, also importantly, with incoming and outgoing teachers and with the administration of partners' universities.

With incoming students, demands are quite natural on an administrative level. It is the most frequent communication at the beginning and end of a mobility event for each student. In this paper, we will present some experiences and suggested solutions. First, we will present the subject of intercultural awareness; experiences with some common problems will follow. Finally, in the conclusion we plan to propose some solutions.

\section{Intercultural Awareness in Mobility}

Intercultural awareness recognizes that people are shaped by their own cultural background, and that this influences how people interpret the world around them and how they perceive themselves and relate to other people. It means that we often view other people's behaviour and benefits through the prism of our own standards of culture. Culture itself is the sum total of ways of living, including behavioural norms, linguistic expressions, styles of communication, patterns of thinking, and beliefs [3]. Our societies are more and more multicultural because of increasing mobility and the rise of global enterprises and organizations, which are more and more multilingual as well as also multicultural [4]. Today, an important part of worldwide business and activities are carried out by international teams and working groups that are characterized by national, professional, corporate and individual cultural diversity [5]. Moreover, the mobility of students and teachers at a university play an important role in the higher-level education process.

The free circulation of people within the EU is supported by a free labour market as well as different programmes and projects have increased student and teacher mobility tremendously [6]. Students are interested in gathering experiences during their studies and placement in an academic period (a Lifelong Learning Programme Erasmus; Programs between the EU and other non-EU countries like Canada, Japan, USA, Australia; Erasmus-Mundus, and some bilateral programs) and a professional (Leonardo da Vinci program) environment. They are also looking for work-based mobility cooperation [7].

These programmes' key objective is supporting the development of innovative action in the member states (all member states of the EU, EFTA states and EU candidate countries) by promoting mobility projects in the context of transnational partnerships, which involve different organizations with an interest in education, training and placement. Transnational partnerships promote the dissemination of expertise and mobility, including language and cultural competencies, which are oriented on promoting language and cultural competencies within the mobility context as well as within society in general [8].

\section{Administrative Experiences in Erasmus Mobility}

The Faculty of Electrical Engineering and Computer Science at the University of Maribor is actively involved in the Erasmus student and teacher exchange programme. We 
have a considerable number of incoming foreign students from different European countries. According to Table 1, the number of foreign students continues to rise from year to year. The number of students almost doubled from the 2006/2007 academic year to the 2007/2008 academic year. The large number of students strains existing problems facing with student mobility. The discussion of problems which arise from the intercultural melting pot caused by students' mobility is a topic that deserves attention. We will focus on the problems of incoming exchange students and our approach to dealing with the problem.

Table 1. Number of Incoming Erasmus Students by Country

\begin{tabular}{|c|c|c|c|c|c|}
\hline Country & $2003 / 2004$ & $2004 / 2005$ & $2005 / 2006$ & $2006 / 2007$ & $2007 / 2008$ \\
\hline Austria & & & & & 1 \\
\hline Belgium & 2 & 1 & 2 & 1 & 4 \\
\hline Bulgaria & 1 & & & & \\
\hline Czech rep. & 2 & & & & 2 \\
\hline Finland & 1 & 3 & 3 & 2 & 4 \\
\hline France & 8 & 4 & 7 & 6 & 7 \\
\hline Greece & & & & 1 & \\
\hline \multicolumn{6}{|l|}{ Croatia } \\
\hline Germany & 1 & 5 & 1 & & \\
\hline Netherlands & & 1 & & & \\
\hline Poland & & & & & 1 \\
\hline Portugal & 2 & 2 & 7 & 3 & 8 \\
\hline Romania & & 2 & & & \\
\hline Slovak rep. & & & 1 & & 2 \\
\hline Spain & 7 & 4 & 10 & 8 & 16 \\
\hline Turkey & & 5 & 3 & 6 & 8 \\
\hline Summary & 24 & 27 & 34 & 27 & 53 \\
\hline
\end{tabular}

At the university level, the standard procedure for all Erasmus participants (incoming and outgoing) is defined. At first, students have to apply via an electronic web form, which is common for the whole university. In addition to the electronic version, they have to print out the form and send it by mail to the university. The application also includes the learning agreement with a list of lectures available at the host university (in our case the University of Maribor) which the student will take. After the application is received at the university, it is sent to the faculties that have to check the learning agreement and approve or reject the student. The first problem arises with the lectures chosen by incoming students. During the period in which the foreign student applies for the Erasmus exchange and until participating in the Erasmus mobility programme, several students have already passed a specific lecture at their university. Since a foreign student needs the written consent of the Erasmus coordinator at the host and home university when changing lectures, the procedure of choosing the lectures can be considerably protracted. In the worst case, this can lead to the situation where an exchange student can only participate in the lecture later during the semester (e.g. after a week's delay). 
Most incoming students finish the lecture which they planned to perform at the beginning of their exchange, but they often face additional hurdles. The biggest problem they face is the language barrier. Although the lectures are conducted in English, many of them lack a proficient knowledge of English. Often their study obligations are left aside until the end of the semester as they first have to learn more English in order to be able to pass a specific lecture. However, this means that all their obligations regarding their study are accumulated at the end of the semester. This constitutes a problem when dealing with exchanged lectures.

Before leaving the foreign exchange, the students have to get all their documents approved by the host institution's coordinator, as required by their home university. The documents required by specific universities are very similar in content, but vary in form. The difference in application forms vary from different cultural background to the experience of a specific university. When leaving the host university, students receive a transcript of record which contains data about the work they accomplished during the exchange period (lectures passed, diploma work preparations, etc.). The whole procedure could be made easier if unified forms could be implemented for all institutions on the level of the Erasmus student mobility programme.

In order to counter some of these obstacles, different approaches were applied at our university, i.e. at the faculty. To give incoming exchange students a good starting point, web pages for incoming Erasmus students were developed at the university level and at the faculty level [1], [2]. Their aim is to ease the whole procedure for foreign students, from the filling out of application forms to the information that is offered for foreign students, while also containing culturally specific habits. In addition to the online material available, a variety of printed information and application material is offered to incoming students both at the university level and the faculty level. However, online communications cannot always replace live communication and therefore office hours for consultation and additional support for incoming exchange students are offered. Aside from the information available online, the printed and live communication, incoming exchange students are offered Slovene language courses for those who are eager to learn the language and the culture of their host country.

Another important aspect is the training and education offered to domestic students and teachers dealing with different aspect of cross-cultural problems, intercultural dialogue and the connection to the Erasmus mobility programme. The training is supported by different materials, which help complete the support for domestic teachers and students dealing with incoming students.

\section{Conclusion}

In the paper we discussed the cross-cultural aspects and problems arising from the Erasmus mobility programme. Intercultural problems arise from the interactions between incoming students and teachers, employees and students at the host institution. In order to try to sanitize or mitigate the problems, the following solutions were implemented by our institution: a homepage dedicated to the Erasmus mobility programme, which is supported by additional printed material (e.g. brochures), and solid communication between foreign students and domestic personnel involved in the 
Erasmus mobility programme. Additionally, language courses are offered to both incoming and outgoing students. However, not only are incoming students educated, but also domestic personnel and students. This education includes training for teachers, personnel and students in topics of intercultural awareness and cross-cultural communication, which are a vital aspect in preventing cross-cultural problems with the Erasmus mobility programme.

A good example of how to deal with intercultural awareness and cross-cultural communication was made by the Valuertech programme [9]. Such research would have to be extended to a variety of areas in order to better cope with the issues and problems of our increasingly multicultural society.

\section{References}

1. University of Maribor Erasmus web pages, https : / / help.uni-mb.si/Socrates / Enter.asp (last visited 7.8.2009)

2. Faculty of electrical engineering and computer science Erasmus web pages, http: / / erasmus. feri.uni-mb.si/ (last visited 7.8.2009)

3. Jandt, F.W.: An introduction to Intercultural Communication - Identities in a Global community. Sage Publication, Thousand Oaks (2004)

4. Lewis, R.D.: When Cultures Collide. Managing Successfully Across Cultures. Nicholas Brealey Publishing, London (1999)

5. Jakkola, H., Heimbürger, A.: Cross-Cultural Software Engineering, MIPRO 2009, Opatija (2009)

6. Magnan, M.: Valeurtech, a Leonardo Pilot Project: Highlighting Professional Experience Acquired in Undergraduate Technology Programmes. In: EAIE Vienna Conference September 10-13, 2003, Session 4.14 (2003)

7. Welzer, T., Brumen, B., Udir, K., Stanjko, R.: Work Based Cooperation. In: International Conference Information Society, Ljubljana (2004)

8. Welzer, T., Brumen, B., Stanjko, R., Breznik, D.: Project VALEURTECH - How to Support Young People for Professional Training in Different Countries. In: Inter Symp. 2003, Baden-Baden (2003)

9. Fleck, J., Beaumier, N., Magnan, M.: Valeurtech, working towards standards to organise and highlight student mobility. In: 3rd International Conference on New Horizons in Industry and Education, August 2003, pp. 28-29 (2003) 